\title{
A method for stable carbon isotope ratio and concentration measurements of ambient aromatic hydrocarbons
}

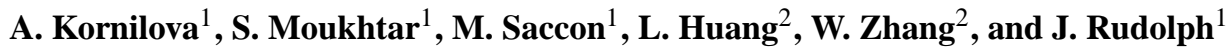 \\ ${ }^{1}$ Centre for Atmospheric Chemistry, York University, Toronto, ON, M3J 1P3, Canada \\ ${ }^{2}$ Environment Canada, Toronto, ON, M3H 5T4, Canada \\ Correspondence to: J. Rudolph (rudolphj@yorku.ca)
}

Received: 17 November 2014 - Published in Atmos. Meas. Tech. Discuss.: 30 January 2015

Revised: 22 April 2015 - Accepted: 28 April 2015 - Published: 4 June 2015

\begin{abstract}
A technique for compound-specific analysis of stable carbon isotope ratios and concentration of ambient volatile organic compounds (VOCs) is presented. It is based on selective VOC sampling onto adsorbent-filled cartridges by passing large volumes of air (up to $80 \mathrm{~L}$ ) through the cartridge. The hydrocarbons are recovered by thermal desorption followed by two-step cryogenic trapping and then are separated by gas chromatography in the laboratory. Once separated, individual VOCs are subjected to online oxidation in a combustion interface and isotope ratio analysis by isotope ratio mass spectrometry. The method allows measurements of stable carbon isotope ratios of ambient aromatic VOCs present in low pptV to ppbV levels with an accuracy of typically better than $0.5 \%$. The precision of concentration measurements is better than $10 \%$. Examples of measurements conducted as part of a joint Environment Canada-York University (EC-YU) measurement campaign at a semi-rural location demonstrate that the ability to make accurate measurements in air with low VOC mixing ratios is important to avoid bias from an overrepresentation of samples that are strongly impacted by recent emissions.
\end{abstract}

\section{Introduction}

Volatile organic compounds (VOCs) comprise an important class of atmospheric pollutants emitted in large quantities from anthropogenic and biogenic sources (Atkinson, 2000; Guenther et al., 2000; Niedojadlo et al., 2008; Piccot et al., 1992; Rudolph, 2002; Sawyer et al., 2000). While their atmospheric mixing ratios are mostly in the ranges of pptV to $\mathrm{ppbV}$, these compounds play an important role in tropo- spheric chemical processes (Atkinson, 2000; Jordan, 2009; Kleinman et al., 2003). Aromatic VOCs are important constituents of urban and rural air masses (Forstener et al., 1997; Lurmann and Main, 1992). These compounds, mostly originating from fossil fuel use, are found in evaporated gasoline, fuels and solvents, vehicle exhaust and many other anthropogenic-related emissions (Hurley et al., 2001; Jang and Kamens, 2001; Reimann and Lewis, 2007). A large fraction of urban VOCs are composed of aromatic compounds, up to 60 to $75 \%$ of which are benzene, toluene, ethylbenzene and 1,2,4-trimethylbenzene (Jang and Kamens, 2001; Smith et al., 1998). The atmospheric oxidation of these aromatics by reaction with $\mathrm{OH}$ and $\mathrm{NO}_{3}$ can result in formation of ozone as well as oxygenated and nitrated products that can contribute to the formation of secondary organic aerosol (Forstener and Flagan, 1997; Jang and Kamens, 2001).

In the atmosphere, VOCs undergo various chemical and physical processes that lead to their transformation, removal, transport and re-distribution (Atkinson, 2000; Helmig et al., 2008; Jenkin and Clemitshawb, 2000; Parrish et al., 2007). The majority of the presently used methods use concentration measurements as an indicator of photochemical processing of VOCs. However, since mixing of air parcels of different origin is a complex and dynamic process, the use of concentration alone as a marker for photochemical processing is problematic (Parrish et al., 2007). The interpretation of the results is quite challenging due to the complexity of atmospheric processing and mixing, and thus many conclusions are made based on a substantial number of assumptions (de Gouw et al., 2005; Gelencsér et al., 1997; Jobson et al., 1998). The change in relative composition of the ambient samples is considered to be a better indicator of chemical 
processing, since the concentration ratios are less affected by physical mixing and dilution (Honrath et al., 2008; Kleinman et al., 2003; McKeen and Liu, 1993; McKeen et al., 1996; Parrish et al., 2007; Roberts et al., 1984; Rudolph and Johnen, 1990), but still requires several assumptions about the history of the studied air mass. It was recently shown that the use of the stable carbon isotope ratios of VOCs requires very few and easily tested assumptions and therefore is more useful in providing insights into photochemical transformation and mixing of VOCs in ambient air (Goldstein and Shaw, 2003; Roberts et al., 1984; Rudolph and Czuba, 2000; Rudolph et al., 2002, 2003; Rudolph, 2007; Stein and Rudolph, 2007).

Measuring the isotope composition of VOCs in the atmosphere is challenging due to the high precision and accuracy necessary to derive meaningful information. Rudolph et al. (1997) published a method for compound-specific determination of the stable carbon isotopic composition for atmospheric VOCs at sub-ppbV levels. The uncertainty of measured isotope ratios was close to $0.5 \%$, and Rudolph et al. (1997) suggested that further improvements in method may allow a precision close to $0.1 \%$. Within several years different research groups published results of stable carbon isotope measurements for a variety of atmospheric VOCs (Anderson et al., 2004; Czapiewski et al., 2002; Iannone et al., 2003, 2005; Irei et al., 2006; Norman et al., 1999; Rogers and Savard, 1999; Rudolph et al., 2002, 2003; Smallwood et al., 2002; Thompson et al., 2003). Nevertheless, the number of publications on isotopic composition measurements and their application is still quite limited due to the need for elaborate and expensive experimental techniques and challenging data interpretation (Eckstaedt et al., 2011; Fisseha et al., 2009; Giebel et al., 2010; Iannone et al., 2005, 2009, 2010; Irei et al., 2006; Li et al., 2010; Moukhtar et al., 2011). An overview of existing techniques to measure stable carbon isotope ratios of VOCs is given in a recent paper (Gensch et al., 2014).

Most of the online techniques used for measurements of the stable carbon isotope composition include a combination of a combustion interface, a gas chromatograph (GC) and an isotope ratio mass spectrometer (IRMS) (Matthews and Hayes, 1978). In addition, for gaseous compounds, sample purification, pre-concentration and separation steps are frequently added (Anderson et al., 2003; Czapiewski et al., 2002; Rudolph et al., 2002; Iannone et al., 2007, 2010; Redeker et al., 2007). While VOC analysis by GC-IRMS is well established, collecting ambient VOC for the isotope analysis is challenging. One of the requirements for accurate GC-IRMS measurements is sufficient mass, which is usually 3 to $5 \mathrm{ng}$ carbon for each analyzed VOCs (Goldstein and Shaw, 2003; Rudolph, 2007; Thompson, 2003). Consequently, compounds that are present at low pptV levels need to be extracted from $30 \mathrm{~L}$ of air or more. Many of the currently reported stable carbon isotope ratio data for ambient VOCs were obtained using whole air sampling in stainless steel canisters, which is adequate when measuring VOCs at $\mathrm{ppbV}$ and high pptV mixing ratios such as for source studies or polluted areas (Czapiewski et al., 2002; Redeker et al., 2007; Rudolph et al., 1997, 2002; Saito et al., 2002). However, collecting whole air samples with the large volumes required for measurement of isotope ratios for VOC mixing ratios well below $1 \mathrm{ppbV}$ is technically challenging (Wintel et al., 2013).

Cryogenic sampling has been used to collect VOCs from very large volumes of air (Bill et al., 2004 Iannone et al., 2007; Zuiderweg et al., 2011), but the technical and logistical challenges for field sampling are substantial. Selective sampling on adsorbent cartridges is a widely used inexpensive method for measurement of VOC concentrations and has recently been applied to collect VOC samples for isotope ratio analysis (Eckstaedt et al., 2011, 2012). However, this sampling technique suffered from substantial sample breakthrough problems for volumes exceeding $3 \mathrm{~L}$. Although it was shown that breakthrough did not significantly impact isotope ratios, the relatively low breakthrough volume substantially restricts the useable sample volume. Furthermore, breakthrough would seriously affect the ability to measure concentrations and isotope ratios in the same sample.

In this article a method for the sampling and isotope ratio analysis of ambient VOCs from large air volumes is presented. It is based on selective sampling of atmospheric compounds onto cartridges filled with an adsorbent (Carboxen 569). Thermal desorption of VOCs from the cartridges is followed by two-step cryogenic trapping, separation by GC and online analysis by IRMS. Various validation tests were conducted and the results will be discussed. A brief overview of results from measurements at a semi-rural location will be given.

\section{Materials and method}

\subsection{Overview}

Ambient VOCs were analyzed for concentration and isotope ratios $\left(\delta^{13} \mathrm{C}\right)$ using the following steps: (1) collection onto adsorbent packed cartridges, (2) thermal desorption of VOCs in a furnace at $553 \mathrm{~K}$ in a flow of high purity helium, (3) a two-stage preconcentration, (4) chromatographic separation, (5) combustion to $\mathrm{CO}_{2}$ and $\mathrm{H}_{2} \mathrm{O}$ in a furnace at $1173 \mathrm{~K}$ and (6) analysis of the $\mathrm{CO}_{2}$ isotopologues by isotope ratio mass spectrometry (IRMS).

\subsection{Sampling}

Selective VOC sampling from volumes between 20 and $80 \mathrm{~L}$ of ambient air was done on adsorbent-filled cartridges. The cartridges were made by filling stainless steel tubes of 13 to $15 \mathrm{~cm}$ in length and $1 / 4^{\prime \prime}$ outer diameter (OD) (inner diameter (ID) of approximately $5 \mathrm{~mm}$ ) (Swagelok, Canada), with $1 \mathrm{~g}$ $( \pm 0.2 \mathrm{~g})$ of Carboxen 569 (Supelco Inc., Bellefonte, USA). 
To keep the adsorbent in place, both ends were plugged with $0.3 \mathrm{~g}( \pm 0.1 \mathrm{~g})$ of quartz wool (Restek, USA). Both ends of the tubes were equipped with $1 / 4^{\prime \prime}$ stainless steel Swagelok nuts, which were closed with $1 / 4^{\prime \prime}$ stainless steel caps during storage and transportation.

Cartridges were cleaned at temperatures between 523 and $573 \mathrm{~K}$ in a furnace while continuously purging them with a flow of 160 to $200 \mathrm{~mL} \mathrm{~min}^{-1}$ of pure helium for at least $24 \mathrm{~h}$. Used cartridges were cleaned for 12 to $24 \mathrm{~h}$. Cleaned cartridges were capped and stored at room temperature in closed glass containers. Some of the cleaned cartridges were analyzed without sampling to determine blank values, as well as the influence of storage, transport and possible material degradation during use.

For sampling, one end of the sampling cartridge was connected to a $1 / 4^{\prime \prime}$ OD stainless steel inlet line (Swagelok, Canada) and the other end to a mass flow controller with a flow totalizer and a pump. To prevent physical damage, the sampling equipment was placed inside a temperaturecontrolled housing. The sampling flow rate was varied between 10 and $50 \mathrm{~mL} \mathrm{~min}^{-1}$, depending on the required sampling time and volume. Typically the sampled air volume ranged from 30 to $50 \mathrm{~L}$. For sampling under conditions of very high humidity, a stainless steel water trap was added to the sampling line. The water trap was cooled by a portable ice machine (Polar by Greenway, USA) to approximately $290 \mathrm{~K}$. Condensed water was removed from the trap at regular intervals, depending on sampling flow rate and ambient humidity, using a removable plug at the bottom of the trap.

Trapping efficiency of Carboxen 569 was tested by sampling ambient air through two cartridges connected in series. Stability of VOCs sampled on cartridges was tested by loading cartridges with test mixtures and analyzing them after storage at room temperature or in the freezer.

\subsection{Sample processing}

\subsubsection{VOC desorption}

VOCs were extracted from the cartridges by thermal desorption. The cartridge was connected to a helium supply line on one end and to a preconcentration system on the other by $1 / 16^{\prime \prime}$ OD heated SS tubing. During desorption the cartridge was placed in the center of a temperature-controlled $30 \mathrm{~cm}$ long ceramic furnace (Omega, USA). Standard conditions for cartridge analysis were $555 \mathrm{~K}$ for $40 \mathrm{~min}$ with a carrier gas flow rate between 60 and $80 \mathrm{~mL} \mathrm{~min}^{-1}$. A range of conditions were tested to identify optimum conditions. The flow rate of the carrier gas was varied from 30 to $100 \mathrm{~mL} \mathrm{~min}^{-1}$, the desorption temperature from 523 to $623 \mathrm{~K}$ and the desorption time from 10 to $50 \mathrm{~min}$.

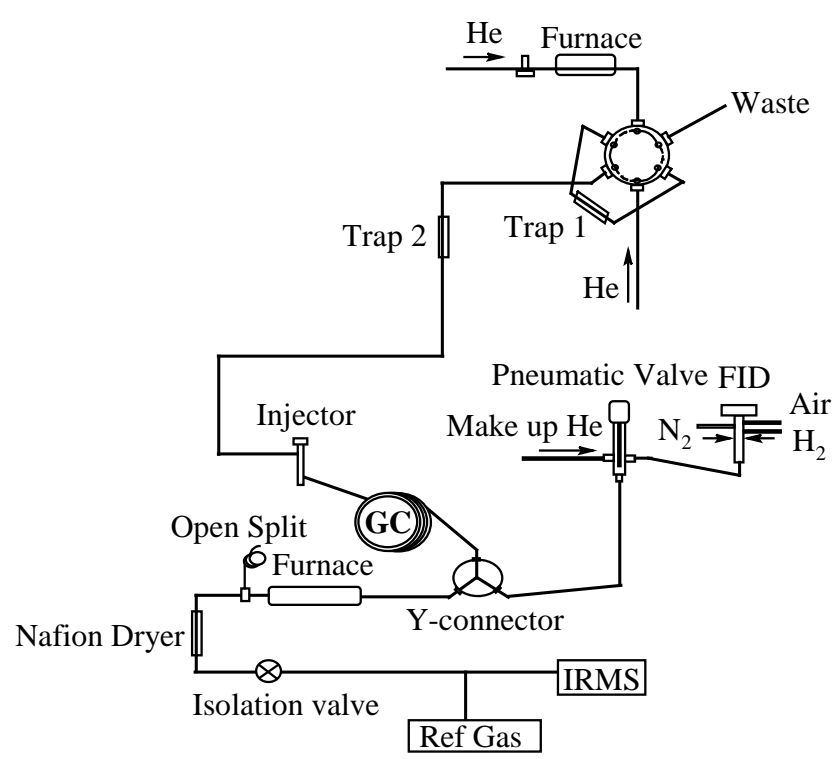

Figure 1. Schematic diagram of the two-stage preconcentration system.

\subsubsection{Two-stage preconcentration}

Desorbed VOCs were cryogenically trapped from the helium gas flow using a custom build two-stage preconcentration system (TSPS) (Fig. 1) similar in design to the method described by Rudolph et al. (1997). It contained two cryogenic traps: one (Trap 1) is a U-shaped 1/8" OD stainless steel tube filled with glass beads (60/80 mesh, Chromatographic Specialties Inc., Canada); the other (Trap 2) consisted of a $15 \mathrm{~cm}$ long piece of $1 / 32^{\prime \prime}$ DB-1 capillary column placed in a $1 / 16^{\prime \prime}$ OD stainless steel tube. The GC column was connected with a Valco zero volume connector (VICI, USA) to a $1 / 32^{\prime \prime}$ stainless steel tube that was attached to a six-port valve. The heating of transfer lines and the valve were individually temperature controlled using temperature sensors (Quick Disconnect Thermocouple Assembly with $12^{\prime \prime}$ and $18^{\prime \prime}$ length and $1 / 16^{\prime \prime}$ diameter 304 stainless steel probes (Omega, USA)) and were constantly maintained at $473 \mathrm{~K}$. For cooling, Trap 1 was immersed in liquid nitrogen (10 to $13 \mathrm{~cm}$ deep), and Trap 2 was cooled by a liquid nitrogen flow that was controlled by a solenoid valve.

The two-position six-port valve was used to direct the gas and sample flow either through Trap 1 (Position A) or bypassing Trap 1 (Position B). At the start of the analysis sequence the six-port valve was set to Position B and the cartridge was flushed with pure helium for $5 \mathrm{~min}$. At the same time Trap 1 was cooled to $97 \mathrm{~K}$. During desorption, the valve was set to Position A and desorbed VOCs were transferred in a flow of helium to Trap 1, where they were adsorbed on the glass beads. At the end of this stage, Trap 2 was cooled to $97 \mathrm{~K}$ and the valve was rotated back to Position B, directing the GC carrier gas through rapidly heated Trap 1 (423 K) 
to Trap 2. After 7 min, Trap 2 was flash heated to $493 \mathrm{~K}$ by applying approximately $2.5 \mathrm{~V}$ to the $1 / 16^{\prime \prime} \mathrm{OD}$ stainless steel tube for $7 \mathrm{~min}$, injecting the VOCs into the GC column. For testing purposes, temperatures of the traps were varied between 93 and $123 \mathrm{~K}$ for trapping and 393 and $513 \mathrm{~K}$ for desorption.

\subsubsection{Gas chromatographic separation and VOC combustion}

The separation was performed in a HP5890 Series II gas chromatograph equipped with a DB-1 column $(100 \mathrm{~m}$, $0.25 \mathrm{~mm}$ ID, $0.5 \mu \mathrm{m}$ film thickness). The VOCs were focused on the head of the column at $298 \mathrm{~K}$ for $10 \mathrm{~min}$, then the oven was heated at $2 \mathrm{~K} \mathrm{~min}^{-1}$ to $323 \mathrm{~K}$ followed by heating at $3 \mathrm{~K} \mathrm{~min}^{-1}$ to $363 \mathrm{~K}$ and then at $10 \mathrm{~K} \mathrm{~min}^{-1}$ to $403 \mathrm{~K}$. The column temperature was then maintained at $403 \mathrm{~K}$ for $10 \mathrm{~min}$. At the end of each analysis the oven temperature was raised to $473 \mathrm{~K}$ and kept at this temperature for 10 to $20 \mathrm{~min}$. Helium was used as carrier gas with the flow rate controlled by an electronic pressure controller at approximately $2 \mathrm{~mL} \mathrm{~min}^{-1}$. Once separated in the GC column, the column effluent was directed either to the flame ionization detector (FID) or the combustion interface by opening or closing a pneumatic valve as shown in Fig. 1.

The combustion interface consisted of a $1 / 4^{\prime \prime}$ ceramic tube ( $0.5 \mathrm{~mm}$ ID, $44 \mathrm{~cm}$ length) with copper, nickel and platinum wires inside. Helium containing traces of oxygen was added as a makeup gas at the inlet of the furnace to prevent peak tailing and to provide oxygen. During analysis the interface was kept at $1223 \mathrm{~K}$, and $\mathrm{CuO}$ and $\mathrm{NiO}$ formed on the wire surfaces converted VOCs into $\mathrm{CO}_{2}$ and $\mathrm{H}_{2} \mathrm{O}$. The oxide layers on the $\mathrm{Cu}$ and $\mathrm{Ni}$ wires were regenerated every night by flushing the furnace and adjacent tubing with the $\mathrm{He}-\mathrm{O}_{2}$ mixture while reducing the interface temperature to $823 \mathrm{~K}$. A flow restrictor split (Fig. 1) was used in an open split configuration to direct between 10 and $20 \%$ of the flow through a Nafion Dryer $(25 \mathrm{~cm}, 0.6 \mathrm{~mm}$ ID, $0.8 \mathrm{~mm}$ OD) into the IRMS.

\subsection{Isotope ratio mass spectrometry and $\delta^{13} \mathrm{C}$ determination}

$\mathrm{CO}_{2}$ was analyzed by IRMS (GV Instruments, Manchester, UK) by detection of $m / z 44,45$ and 46 . The isotope ratios ${ }^{45} \mathrm{R}$ and ${ }^{46} \mathrm{R}$ were determined from the peak areas (A) for the individual $m / z$ ratios as described by Rudolph (2007): ${ }^{45} \mathrm{R}=\frac{A\left[{ }^{45} \mathrm{CO}_{2}\right]}{A\left[{ }^{44} \mathrm{CO}_{2}\right]}$ and ${ }^{46} \mathrm{R}=\frac{A\left[{ }^{46} \mathrm{CO}_{2}\right]}{A\left[{ }^{44} \mathrm{CO}_{2}\right]} \cdot{ }^{46} \mathrm{R}$ was used for correction of the ${ }^{45} \mathrm{R}$ for the contribution from ${ }^{12} \mathrm{C}^{16} \mathrm{O}^{17} \mathrm{O}$ (Craig, 1957; Santrock et al., 1985).

Peak integration was done manually using a method similar to that described by Rudolph et al. (1997). To minimize bias due to the manual definition of peak boundaries, each peak was integrated 10 times with start and end points varying every time by $0.1 \mathrm{~s}$. This allowed verification that averaged delta values were not significantly biased by the choice of peak boundaries. All target VOCs, except p- and mxylene, were completely separated. Due to their partial overlap the peaks for $\mathrm{p}$ - and $\mathrm{m}$-xylene were integrated together.

Throughout the run, reference $\mathrm{CO}_{2}$, calibrated relative to the V-PDB (Vienna Peedee Belemnite) standard, was introduced several times directly into the IRMS in pulses of 20 to $40 \mathrm{~s}$ duration. Between three and five reference gas injections were made while the pneumatic valve was open and the flow from the GC column was directed to the FID at the beginning and at the end of each run. Between four and seven injections were made between peaks during the chromatographic separation while the flow from the GC column was directed to the combustion interface and IRMS.

\subsection{Validation tests}

Gaseous test mixtures of target VOCs were prepared in stainless steel canisters with VOC mixing ratios in the ppbV to ppmV range by injecting known quantities of pure VOCs and diluting with helium. The VOC concentration in these test mixtures ranged from $0.1 \mathrm{ng} \mathrm{cm}^{-3}$ to $0.7 \mu \mathrm{g} \mathrm{cm}^{-3}$ (15 ppbV to $1.7 \mathrm{ppmV})$. All mixtures were quantified using a standard mixture of VOCs (ppbV levels) provided by the National Research Council of Canada (NRC). VOCs used to prepare gaseous mixtures were individually combusted at high temperatures in vacuum-sealed tubes containing $\mathrm{CuO}$. The resulting $\mathrm{CO}_{2}$ was cryogenically separated, extracted and later analyzed by IRMS, using a dual-inlet system, to determine their $\delta^{13} \mathrm{C}$ values. These offline isotope ratios were benzene $-28.40 \pm 0.02 \%$, toluene $-27.02 \pm 0.07 \%$, ethylbenzene $-26.84 \%$, p-xylene $-25.69 \pm 0.05 \%$, m-xylene $-26.92 \%$ and o-xylene $-28.16 \pm 0.07 \%$. Standard deviations for ethylbenzene and m-xylene cannot be given since repeat measurements are not available. These mixtures were used for calibration as well as determination of the accuracy of the $\delta^{13} \mathrm{C}$ measurements.

A number of tests were conducted to optimize and evaluate the accuracy and reproducibility of the method. Operation conditions and instrument performance were tested weekly using mixtures with known composition and isotope ratios. Precision of the system was determined by the reproducibility of peak areas from repeat measurements of the test mixtures. Accuracy of isotope ratio measurements was tested by comparing $\delta^{13} \mathrm{C}$ values determined online for the test mixtures and offline for the individual VOCs.

\section{Results and discussion}

The components of the sampling and analysis system were tested under different operational conditions. Here, the most important results of the optimization and validation tests are presented and discussed. 


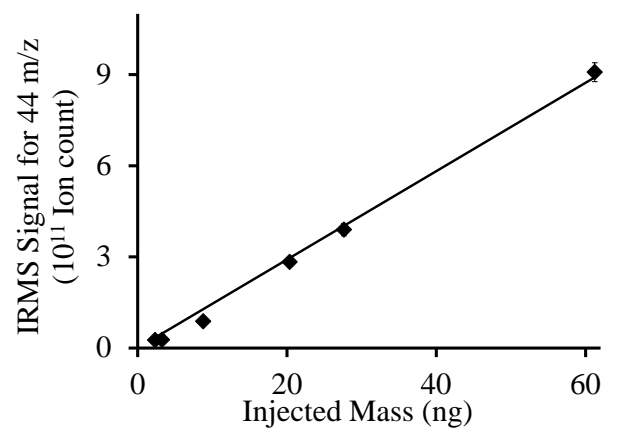

Figure 2. Calibration curve for toluene (based on TSPS-GC-IRMS measurements, slope $=1.46 \times 10^{10} \pm 0.03 \times 10^{10}$ ions ng $^{-1}, R^{2}=$ 0.997)

\subsection{Reproducibility, accuracy and linearity of the TSPS-GC-IRMS system}

Performance assessment of the TSPS was based on injections of gaseous mixtures directly into the TSPS. On average, the relative standard deviation $(\%)$ of peak areas from repeat measurements (> 10 repeats) was $5.3 \%$, with $4 \%$ for alkanes and $6 \%$ for aromatic compounds. For all targeted compounds, calibration curves were constructed with intercepts for regression set to 0 . In most of the linear regression analysis the correlation coefficient $\left(R^{2}\right.$ value) was $>0.99$. The intercept was set to 0 since intercepts in linear regressions allowing nonzero intercepts did not significantly differ from 0 . An example of a calibration curve is shown in Fig. 2. The sensitivity of the GC-IRMS measurements was in the range

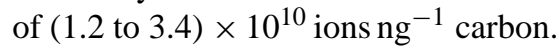

Figure 3 shows the measured $\delta^{13} \mathrm{C}$ values as a function of sample mass for aromatic VOCs and n-alkanes as well as the $\delta^{13} \mathrm{C}$ values from the offline analysis of bulk VOCs. The standard deviation for repeat measurements of online $\delta^{13} \mathrm{C}$ was mostly lower than $0.3 \%$ : on average $0.2 \%$ for $>10 \mathrm{ng}$ of alkanes and $0.3 \%$ for $>1 \mathrm{ng}$ of aromatics. Generally the standard deviation was lower for higher masses. For masses exceeding $5 \mathrm{ng}$ the measured $\delta^{13} \mathrm{C}$ values were independent of sample mass, but for lower masses the measured values systematically decreased with decreasing mass. The only exception was the combined measurement of $\mathrm{p}$-xylene and $\mathrm{m}$ xylene, where the decrease in measured $\delta^{13} \mathrm{C}$ is already significant at sample masses below $10 \mathrm{ng}$. This is most likely due to the necessity of a wider time window for integration of the two overlapping peaks and the resulting greater impact of baseline drift and baseline noise.

For aromatic VOCs, offline and online values usually agreed for masses of more than 3 to $5 \mathrm{ng}$ per compound within the uncertainty of the measurements (Fig. 3); however, there was a significant bias towards lower delta values for smaller masses. For alkanes a significant difference between offline and online data was observed, even though both
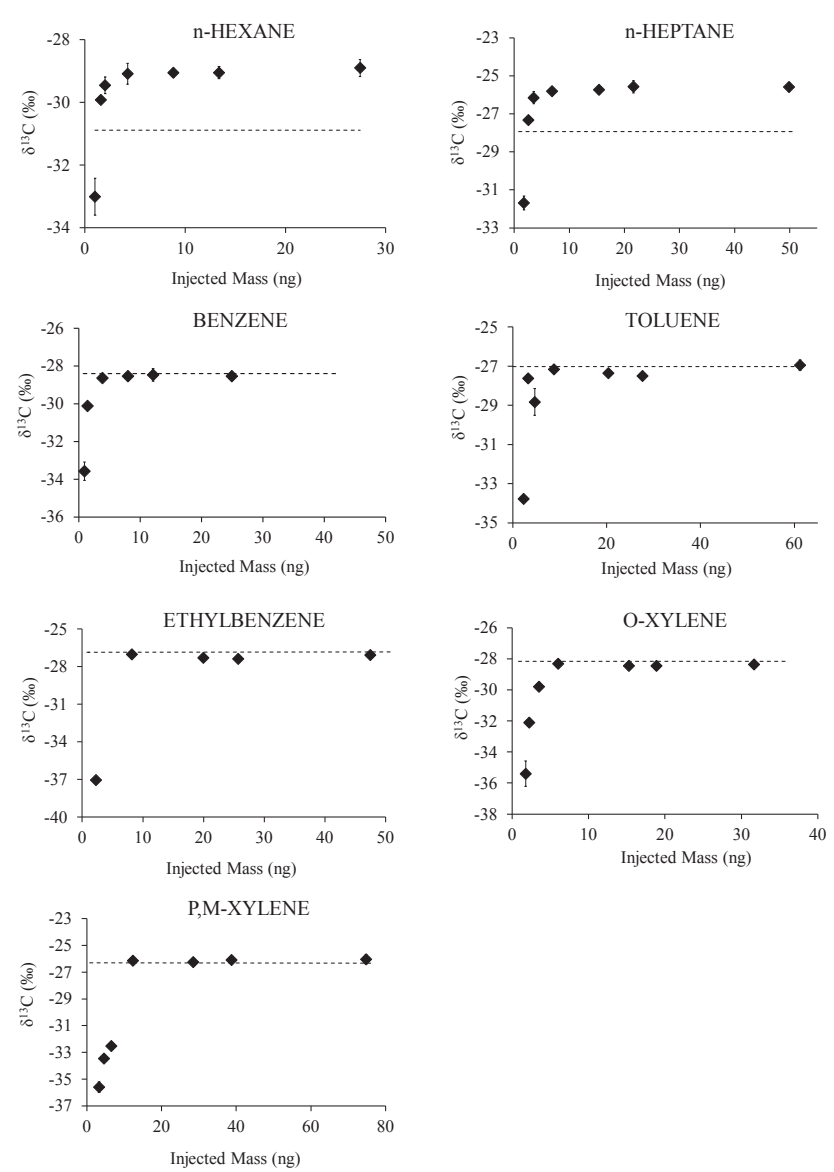

Figure 3. Plot of $\delta^{13} \mathrm{C}$ values versus injected mass measured online using TSPS-GC-IRMS. Dashed lines are the reference (offline) $\delta^{13} \mathrm{C}$ values. For $\mathrm{p}, \mathrm{m}$-xylene the average of the $\mathrm{p}$-xylene and $\mathrm{m}$ xylene offline values is given since the mixtures contained equal masses of both xylenes.

offline and online tests displayed good reproducibility with uncertainties well below the observed difference.

No certified standards or equivalent internationally accepted reference mixtures suitable for tests of the accuracy of isotope ratio measurement of atmospheric VOCs are available, and consequently the accuracy tests had to be conducted using mixtures prepared in-house. In the case of good agreement between GC-IRMS analysis and the isotope ratio of the test mixtures, this gives confidence in the accuracy of the GC-IRMS measurements. However, in case of a systematic discrepancy between offline and GC-IRMS results this makes it difficult to identify the source of bias. While isotope fractionation during sampling on the adsorbent cartridges can be ruled out since the isotope ratios obtained from direct analysis of the test mixtures agreed with isotope ratios determined from samples of the test mixtures collected on adsorbent cartridges, uncertainty in the carbon isotope ratio of the test mixture as well as biased GC-IRMS isotope ratio measurements are possible explanations. 
Table 1. Averages of background signals for cartridges containing $(1 \pm 0.2) \mathrm{g}$ of Carboxen and 0.2 to $0.5 \mathrm{~g}$ of quartz wool.

\begin{tabular}{llcc}
\hline Compound & $\begin{array}{l}\text { Blank } \pm \mathrm{SD}^{\mathrm{a}} \\
(\mathrm{ng})\end{array}$ & $\begin{array}{l}\mathrm{DL}^{\mathrm{b}} \\
(\mathrm{ng})\end{array}$ & $\begin{array}{c}\text { Average mass per } \\
\text { ambient cartridge } \\
(\mathrm{ng})^{\mathrm{c}}\end{array}$ \\
\hline n-Hexane & $0.2 \pm 0.3$ & 1.0 & 146 \\
Benzene & $0.7 \pm 0.5$ & 1.5 & 16 \\
n-Heptane & $1.1 \pm 0.1$ & 0.3 & 64 \\
Toluene & $0.2 \pm 0.1$ & 0.4 & 61 \\
Ethylbenzene & $0.2 \pm 0.2$ & 0.6 & 7 \\
p, m-Xylene & $0.2 \pm 0.2$ & 0.5 & 17 \\
o-Xylene & $0.2 \pm 0.1$ & 0.4 & 5 \\
\hline
\end{tabular}

a SD: SD calculated from at least four repeat measurements.

b $3 \sigma$ detection limit (DL).

c Average calculated from 50 ambient samples.

Error in the $\delta^{13} \mathrm{C}$ in the test mixture can be due to loss or contamination during preparation of the mixture or error in the offline $\delta^{13} \mathrm{C}$ determination for the bulk n-alkanes. Since the mixtures were not prepared for the purpose of calibrating concentration measurements, it is not possible to exclude or verify the existence of losses or contaminations from comparison of peak areas or calibration curves. The uncertainty of conventional dual-inlet $\delta^{13} \mathrm{C}$ measurements in carbon dioxide is much lower than the observed discrepancy in the $\mathrm{n}$-alkane carbon isotope ratios. However, incomplete oxidation of n-alkanes during the offline combustion of the bulk $\mathrm{n}$-alkanes could result in significant carbon isotope fractionation. Since n-alkanes are less reactive than benzene and alkylbenzenes, this would be consistent with the absence of bias for aromatic VOCs.

Bias in the GC-IRMS analysis can be caused by contamination or losses during adsorption or desorption of VOCs in the TSPS, problems in the chromatographic separation such as peak tailing or baseline drift and incomplete oxidation in the combustion interface. A significant impact from contamination or artifacts can be ruled out since this would result in a decrease of bias for high sample masses, which is not found (Fig. 3). Although in principle none of the other explanations can be ruled out, there is no direct evidence which would support them. The good reproducibility of the measured nalkane carbon isotope ratios would require that any loss in the TSPS would be highly reproducible, which is unlikely, and the tests of the TSPS showed no indication for significant loss of n-alkanes in the TSPS. Except for n-pentane there also is no indication of problems due to chromatographic separation, peak shape or baseline drift for n-alkanes. Due to the higher chemical stability of n-alkanes, incomplete oxidation in the combustion interface could result in isotope fractionation for n-alkanes without influencing the results for aromatic VOCs, although this would require inverse isotope effects for the catalytic oxidation of $n$-alkanes in order to explain the bias towards higher carbon isotope ratios.

\subsection{Cartridge tests}

The VOC masses observed for analysis of blank cartridges using desorption temperatures in the range of 474 to $573 \mathrm{~K}$ are listed in Table 1 together with their standard deviations and the resulting $3 \sigma$ detection limit. For comparison, the averages of masses of VOCs collected in ambient samples are also given. Tests of individual components of the cartridges showed that the main source of the blanks was Carboxen 569. Stainless steel tubes did not produce any contamination; tests of cartridges containing only quartz wool at temperatures ranging from 295 to $590 \mathrm{~K}$ showed no or only marginal signals. As can be seen from Table 1, the blank values were small compared to typical VOC masses in ambient samples. For the typical sample volume of $30 \mathrm{~L}$ the detection limits correspond to mixing ratios in the range of 3 to $15 \mathrm{pptV}$.

Optimum desorption conditions were determined by analyzing cartridges loaded with approximately 30 to $60 \mathrm{ng}$ of VOCs using the gaseous test mixtures. Desorption times, temperatures and flow rates were varied (Table 2). A flow rate of 50 to $80 \mathrm{~mL}$ was used for most of the tests. Lower desorption temperatures and shorter desorption times (Table 2) resulted in poor recovery of compounds of low volatility. However, the option of using very high temperatures is limited since a prolonged exposure to high temperatures may result in a degradation of the cartridge materials. Since recovery was, within the uncertainty of the measurements, quantitative at $553 \mathrm{~K}$ and $40 \mathrm{~min}$, these conditions were chosen as standard desorption conditions. Table 3 shows the average recovery and its reproducibility for the chosen standard conditions.

Sampling efficiency tests using two cartridges in series showed that for sample volumes of up to $80 \mathrm{~L}$, the second cartridge only contained between 2 and $5 \%$ of the mass found on the first cartridge. These masses often were close to or below the detection limits and therefore only provide an upper limit for breakthrough during sampling.

Capped sample-containing cartridges could be stored both at room temperature for a short period and in a freezer for longer time with no significant loss of VOCs (Fig. 4). Generally the change in mass during storage is less than $10 \%$. Similarly, the isotopic fractionation during storage was less than $0.3 \%$ (Fig. 5). The masses of VOCs loaded for these tests were in the range of 25 to $75 \mathrm{ng}$ (Table 3 ).

\subsection{Ambient measurements}

The newly developed method was applied in an ambient air quality field study in 2009 to 2010 (Kornilova et al., 2013) at Egbert, a semi-rural location in southern Ontario. Details about the sampling site can be found in Kornilova et al., 2013. This paper also contains a detailed discussion of the use of the measured VOC carbon isotope ratios to quantitatively evaluate photochemical VOC processing. Therefore, 
Table 2. Recoveries of VOCs (\%) under different desorption conditions (samples were analyzed with GC-FID or GC-IRMS)*.

\begin{tabular}{lrrrrrrrr}
\hline Test no. & 1 & 2 & 3 & 4 & 5 & 6 & 7 & 8 \\
\hline Duration (min) & 15 & 15 & 15 & 20 & 25 & 30 & 30 & 40 \\
Temperature (K) & 523 & 553 & 573 & 673 & 573 & 573 & 583 & 553 \\
Flow rate (mL/min) & 55 & 53 & 54 & 78 & 58 & 58 & 53 & 60 \\
n-Hexane & 70 & 107 & 164 & 102 & 106 & 104 & 102 & 102 \\
Benzene & 73 & 105 & 148 & 104 & 106 & 105 & 108 & 113 \\
n-Heptane & 39 & 93 & 102 & 99 & 96 & 97 & 96 & 100 \\
Toluene & 43 & 96 & 110 & 103 & 100 & 100 & 102 & 103 \\
Ethylbenzene & 29 & 74 & 77 & 86 & 87 & 86 & 87 & 90 \\
p, m-Xylene & 24 & 65 & 67 & 82 & 90 & 87 & 97 & 95 \\
o-Xylene & 25 & 68 & 64 & 81 & 85 & 84 & 92 & 94 \\
\hline
\end{tabular}

* Results are based on one measurement.

Table 3. Average recoveries ${ }^{\mathrm{a}}$ of VOCs sampled on cartridges for desorption at $553 \mathrm{~K}$ for $40 \mathrm{~min}$ at $(60$ to 80$) \mathrm{mL} \mathrm{min}^{-1}$ carrier gas flow rate.

\begin{tabular}{lrcr}
\hline Compounds & $\begin{array}{r}\text { Mass of } \\
\text { loaded } \\
\text { VOC (ng) }\end{array}$ & $\begin{array}{r}\text { Average } \\
\text { recovery } \\
\pm \text { SD }(\%)\end{array}$ & $\begin{array}{r}\text { SD of } \\
\text { delta values } \\
(\%)\end{array}$ \\
\hline Benzene & 25 & $112 \pm 2$ & 0.6 \\
Heptane & 50 & $93 \pm 9$ & 0.7 \\
Toluene & 60 & $102 \pm 14$ & 0.6 \\
Ethylbenzene & 50 & $84 \pm 13$ & 0.3 \\
p, m-Xylene & 75 & $99 \pm 20$ & 0.6 \\
o-Xylene & 35 & $94 \pm 5$ & 0.5 \\
\hline
\end{tabular}

a Values were not blank corrected.

$\mathrm{b}$ Based on three to four measurements.

c SD: Standard deviation.

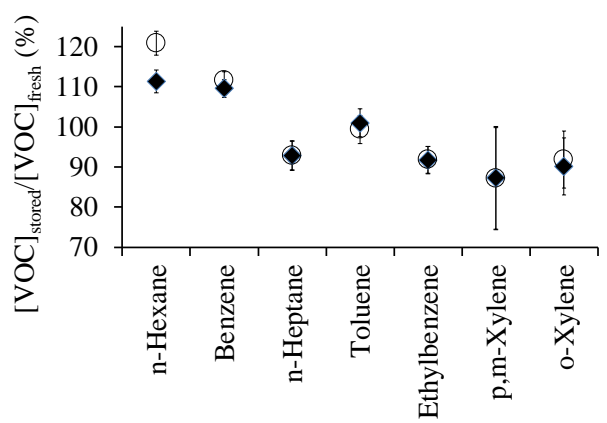

- Ambient (1-2 weeks) $\bigcirc$ Freezer (6-7 months)

Figure 4. Impact of storage on sample recovery for storage of 1 to 2 weeks at ambient temperatures (diamonds) and 6 to 7 months in a freezer (circles). The recovered masses are given relative to samples analyzed immediately after sampling. Both storage tests used the same reference values. Values used are the average of three to four measurements and the error bars show the variability of results for analysis after storage. Masses loaded range from 25 to $75 \mathrm{ng}$. Values were not corrected for blanks.

the discussion here will be limited to aspects related to performance of the analytical method.

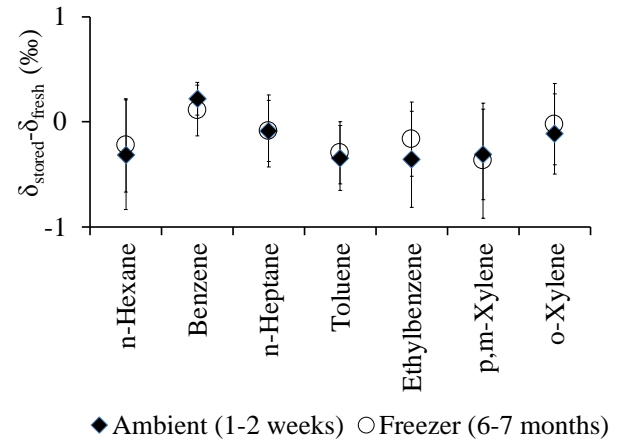

Figure 5. Change in $\delta^{13} \mathrm{C}$ of VOCs collected on cartridges during storage for 1 to 2 weeks at ambient temperatures (diamonds) and 6 to 7 months in a freezer (circles). The differences are given relative to the $\delta^{13} \mathrm{C}$ values of samples analyzed without storage. Both storage tests used the same reference values. Values used are the average of three to four measurements and the error bars show the variability of results for analysis after storage. Masses loaded range from 25 to $75 \mathrm{ng}$. Values were not corrected for blanks.

Example chromatograms for the test mixture and an ambient sample are provided in Fig. 6. For ambient samples, it was found that n-pentane was subject to substantial peak overlap, which prevents reliable peak evaluation. Therefore, to minimize the risk of contamination of the combustion interface and the IRMS, monitoring the column effluent by IRMS started with hexane. Otherwise all target compounds were well separated with the exception of $\mathrm{p}$-xylene and $\mathrm{m}$ xylene, which were integrated as one peak. It should be noted that the change in time window of monitoring the column effluent changes the retention times, especially for peaks eluting early in the time window which is monitored by the IRMS. This is the result of a small counter pressure at the end of the separation column, which results from the gas flow that is used to prevent the column effluent from entering the combustion interface and the resulting lower pressure difference between the head and the end of the separation column. 

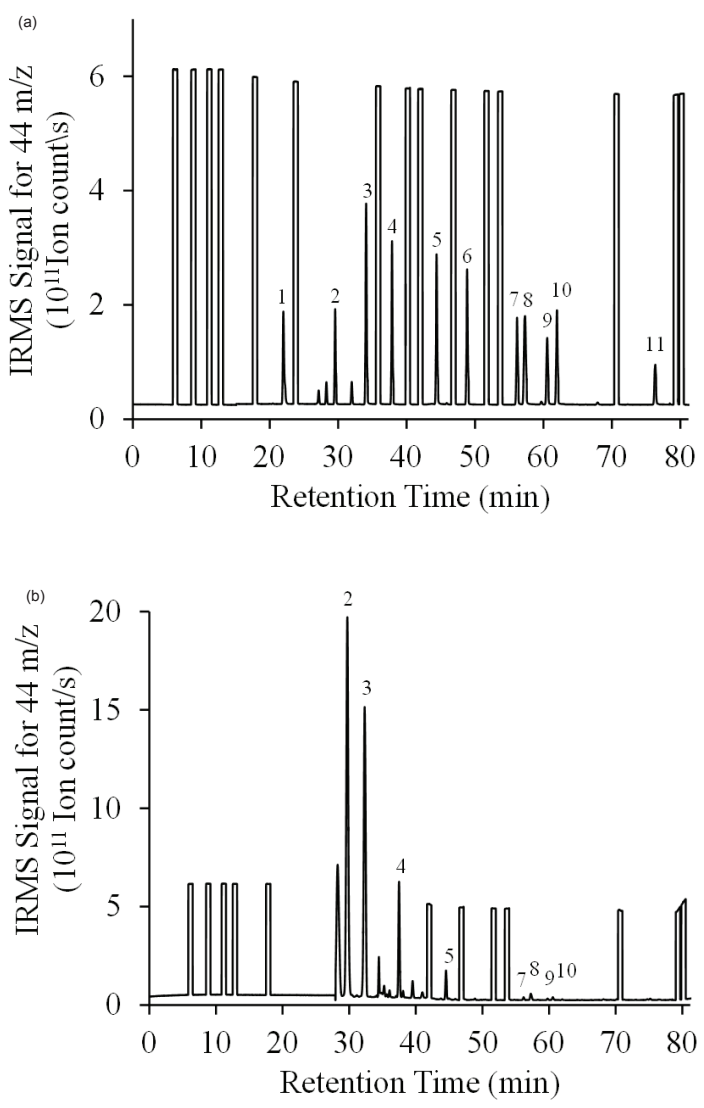

Figure 6. Chromatogram obtained by GC-IRMS for a test mixture with 11 compounds (a) and an ambient sample (b). Rectangular peaks are reference $\mathrm{CO}_{2}$ signals, and peaks numbered from 1 to 11 correspond to n-pentane, n-hexane, benzene, n-heptane, toluene, n-octane, ethylbenzene, p,m-xylene, o-xylene, n-nonane and n-decane.

For most of the samples the peaks for n-octane, n-nonane and $\mathrm{n}$-decane corresponded to masses below the lower limit of the linear range, and for these compounds the number of available data points is too small to allow calculation of meaningful averages. Problems with peak evaluation due to small peak areas were not limited to the $\mathrm{C}_{8}-\mathrm{C}_{10}$ n-alkanes, but occurred less frequently for aromatic VOCs. The total number of samples that could be analyzed for $\delta^{13} \mathrm{C}$ was 50 and the number of $\delta^{13} \mathrm{C}$ measurements available ranges from 46 for benzene to 26 for hexane.

Table 4 gives an overview for concentrations and $\delta^{13} \mathrm{C}$. A comparison between measured $\delta^{13} \mathrm{C}$ and $\delta^{13} \mathrm{C}$ of typical urban VOC emissions, which are also included in Table 7, shows that the measured $\delta^{13} \mathrm{C}$ values generally are heavier than those of typical emissions. This is expected since photochemical processing will typically result in enrichment of ${ }^{13} \mathrm{C}$ (Rudolph et al., 2002; Rudolph and Czuba, 2000). The only exception is hexane: here the lower end of the $\delta^{13} \mathrm{C}$ values are about $1.4 \%$ lower than the $\delta^{13} \mathrm{C}$ values of urban emissions, which is outside of the uncertainty range of
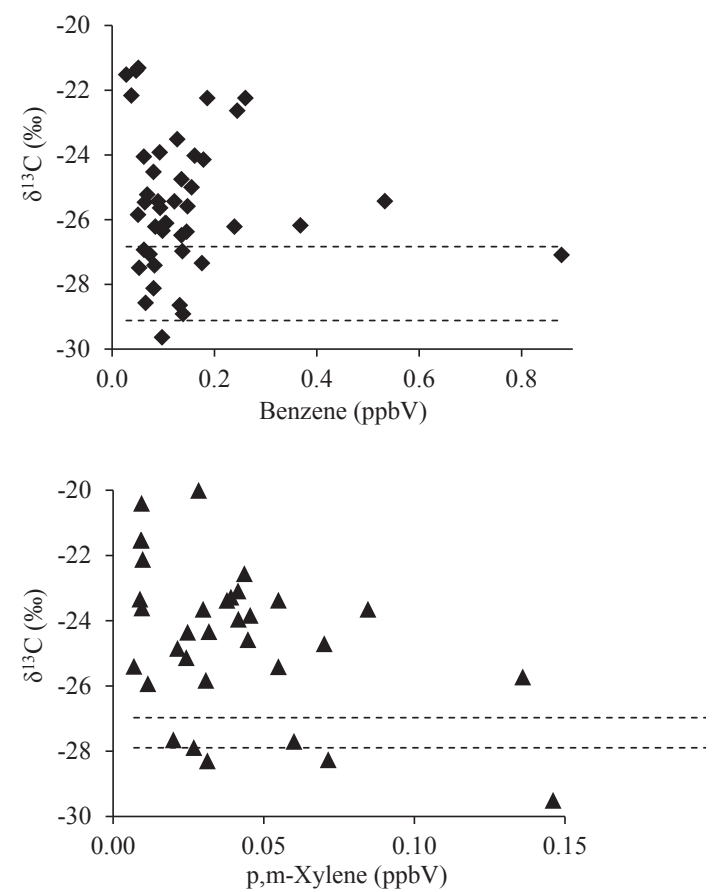

Figure 7. Mixing ratio versus stable carbon isotope ratio plots for samples collected at Egbert. The ranges (average $\pm \sigma$ ) of isotope ratios reported by Rudolph et al. (2002) for urban sources are shown as dashed lines.

known urban emissions and the measurement precision. The possible bias of $n$-hexane online measurements cannot explain this difference since a correction for a possible bias derived from the difference between online and offline results (Fig. 3) would result in an even larger difference, sometimes exceeding $3 \%$. This suggests the existence of a local or regional $\mathrm{n}$-hexane source with a $\delta^{13} \mathrm{C}$ value lower than typical urban emissions. The existence of a substantial unidentified regional $\mathrm{n}$-hexane source is consistent with $\mathrm{n}$-hexane mixing ratios, which are often high compared to that of other VOCs. It should be noted that the results for $\mathrm{n}$-hexane may be biased towards samples at the higher end of mixing ratios due to the significant number of samples for which reliable evaluation of $\delta^{13} \mathrm{C}$ was not possible.

Due to the relatively high sample mass needed for $\delta^{13} \mathrm{C}$ measurement by GC-IRMS bias due to the problem of reliable evaluation of $\delta^{13} \mathrm{C}$ in samples with low concentrations is a potentially significant problem. To evaluate this in more detail, we use results for aromatic VOCs where between 80 and $90 \%$ of the samples could be analyzed for $\delta^{13} \mathrm{C}$. Figure 7 shows the dependence between measured $\delta^{13} \mathrm{C}$ and concentration for benzene and $\mathrm{p}, \mathrm{m}$-xylene. Compared to the $\delta^{13} \mathrm{C}$ values of emissions, the samples are enriched in $\delta^{13} \mathrm{C}$ to various degrees. The number of samples substantially enriched in $\delta^{13} \mathrm{C}$ is higher at low mixing ratios than at high mixing ratios. Although no statistically significant overall trend can be determined due to the substantial seemingly random vari- 
Table 4. Concentrations and delta values determined from ambient samples collected at Egbert.

\begin{tabular}{|c|c|c|c|c|c|c|c|c|}
\hline \multirow[t]{2}{*}{ Compound } & \multicolumn{3}{|c|}{ Concentrations (ppbV) (ambient) } & \multicolumn{3}{|c|}{$\delta^{13} \mathrm{C}_{\text {ambient }}(\% o)$} & \multicolumn{2}{|c|}{$\delta^{13} \mathrm{C}_{\text {source }}(\% o)^{*}$} \\
\hline & Median & 10th percentile & 90th percentile & Median & 10th percentile & 90th percentile & Average & SD \\
\hline n-Hexane & 1.53 & 0.61 & 5.18 & -27.0 & -28.1 & -24.0 & -26.7 & 0.4 \\
\hline Benzene & 0.10 & 0.05 & 0.24 & -25.6 & -27.9 & -22.2 & -28.0 & 1.1 \\
\hline n-Heptane & 0.40 & 0.14 & 1.80 & -24.2 & -26.1 & -21.7 & -26.4 & 1.1 \\
\hline Toluene & 0.13 & 0.06 & 0.25 & -24.8 & -26.7 & -22.5 & -27.6 & 0.6 \\
\hline Ethylbenzene & 0.02 & 0.01 & 0.06 & -23.9 & -27.5 & -18.6 & -27.7 & 0.4 \\
\hline p, m-Xylene & 0.03 & 0.01 & 0.11 & -23.8 & -27.7 & -19.8 & -27.4 & 0.5 \\
\hline o-Xylene & 0.01 & 0.004 & 0.03 & -23.5 & -26.2 & -20.7 & -27.2 & 0.1 \\
\hline
\end{tabular}

* Stable carbon isotope composition of the sources based on Rudolph et al. (2002).

ability of the data, the mean $\delta^{13} \mathrm{C}$ value for the lowest 10 concentrations is $-23.1 \pm 0.1 \%$ (error of mean) for benzene and $-22.9 \pm 0.9 \%$ or for $\mathrm{p}$, m-xylene, which indicates a substantial difference to the average for all measurements, which is $-25.2 \pm 0.1 \%$ and $-25.4 \pm 0.5 \%$ o for benzene and toluene, respectively. This is a strong indication that limitations in making precise $\delta^{13} \mathrm{C}$ measurements at very low mixing ratios can bias the average measured $\delta^{13} \mathrm{C}$ towards lower values. The origin of such bias is easily understood: air with higher mixing ratios of VOCs is more likely to have been subjected to significant recent emissions than clean air.

\subsection{Comparison with existing methods}

Due to the complexity of the existing methods used for sampling and measurements of stable carbon isotope compositions of ambient VOCs, the number of publications on method development and ambient measurements and their interpretation is still quite limited. An overview of existing methods has been given in a recent paper by Gensch et al. (2014). All methods for ambient measurements and emission studies use GC-IRMS for analysis of sampled VOCs, although often details of the chromatographic separation and combustion interface differ. The main difference between the methods is the sampling and VOC enrichment procedure. This is not surprising since the analysis of VOC carbon isotope ratios requires enrichment of VOCs from large sample volumes, which is technically challenging and may require substantial logistic effort in field studies.

In principle, the lower limit of mixing ratios for which meaningful VOC carbon isotope ratios can be conducted depends on the sample volume that can be used. This volume typically ranges from several liters for whole air sampling to several hundred liters or more for cryogenic sampling (Gensch et al., 2014, and references therein). With sample volumes of up to $80 \mathrm{~L}$, the method developed in this work allows collection of significantly larger samples than methods using whole air sampling but not of the extremely large sample volumes that can be used by some cryogenic methods (Bahlmann et al., 2011; Bill et al., 2004; Iannone et al., 2007). However, the adsorptive sampling method described in this paper requires less expensive instrumentation than cryogenic sampling and can be conducted in the field with instrumentation that is similar in requirements (electrical power, weight, storage, shipment) to whole air sampling in pressurized containers.

While adsorptive sampling as described in this paper allows use of larger air sample volumes than whole air sampling, it has some other limitations. Each sample can only be analyzed once, which can be a problem in cases where the mixing ratios in the sampled air are highly variable or the range of mixing ratios expected is unknown, such as in many emission studies. Due to the limited dynamic range of IRMS measurements, sampled VOC masses may be outside of the dynamic range and thus lost. Whole air samples, in principle, allow repeat runs of the same sample using different volumes or IRMS settings. This is very useful for samples with high VOC concentrations but of limited value for very low concentrations since existing methods for whole air sampling do not provide sufficient sample volume for several measurements at sub-ppbV levels.

Collection of whole air samples typically requires less time than adsorptive or cryogenic sampling. This can be a significant advantage if sampling time is limited, for example in airplane-based sampling. However, adsorptive sampling can easily provide samples that are integrated over long time periods. For example, our study at Egbert used 24-hour sampling periods, which allows determination of representative averages without the necessity to collect and analyze an extremely large number of samples. Finally, adsorptive sampling is not suitable for collection of VOCs with very high volatility such as $\mathrm{C}_{2}$ or $\mathrm{C}_{3}$ hydrocarbons.

The reproducibility of isotope ratio measurements for our newly developed method is better than $0.5 \%$, similar to that of other state-of-the-art methods for measurement of $\delta^{13} \mathrm{C}$ in ambient VOCs (Czapiewski et al., 2002; Eckstaedt et al., 2012; Kawashima and Murakami, 2014; Rudolph et al., 1997; Saito et al., 2009; Turner et al., 2006; Wintel et al., 2013); however, the lower limit of concentrations for which 
this precision can be achieved is significantly lower than that achieved by these other methods.

Tests of accuracy for $\delta^{13} \mathrm{C}$ measurements of aromatic VOCs demonstrate that there is no detectable bias, similar to the findings in several other studies (Czapiewski et al., 2002; Eckstaedt et al., 2012; Rudolph et al., 1997; Saito et al., 2009). However, for n-alkanes the GC-IRMS results differ from the offline values for bulk material used to prepare test mixtures by approximately $2 \%$. Unfortunately there are not many published tests of the accuracy of $\delta^{13} \mathrm{C}$ measurements for $\mathrm{C}_{6}$ and heavier n-alkanes in air. Rudolph (2007) summarized results from similar sets of comparisons, which included a wide range of n-alkanes and concluded that in most cases offline and online $\delta^{13} \mathrm{C}$ values agree within the uncertainty of the GC-IRMS measurement. However, in a few cases differences in the range of $1 \%$ were observed, although these differences were statistically not significant.

\section{Summary and conclusions}

The newly developed method for analysis of atmospheric VOCs allows measurement of $\delta^{13} \mathrm{C}$ of light aromatic hydrocarbons with an accuracy and precision of better than $0.5 \%$ o for mixing ratios in the lowest pptV range. For n-alkanes a similar precision could be achieved, but a systematic bias of up to $2 \%$ is possible. The precision of concentration measurements is estimated to be better than $10 \%$. Sampling is done with inexpensive equipment suitable for field work and samples can be stored for more than 1 week under ambient conditions and at least 6 months in a freezer without detectable sample degradation. This allows transport and storage of samples with little logistic effort. Overall, these performance characteristics are a significant improvement over that of other currently available methods.

The methodology has been specifically developed and tested for the purpose of accurate measurement of light aromatic hydrocarbons, but this does not exclude its use for analysis of other VOCs. Tests demonstrated that breakthrough of heavier than $\mathrm{C}_{5}$ VOCs is negligible for up to $80 \mathrm{~L}$ of air, but since no tests have been conducted for larger volumes, collection of VOCs from even larger volumes may be possible with no or little modification of the sampling cartridges.

Tests of the accuracy of carbon isotope ratio measurements of n-alkanes showed a bias of approximately $2 \%$ o between the isotope ratio of test mixtures prepared in-house and GCIRMS measurements. It was not possible to identify whether this is due to uncertainty in the isotope ratio of the test mixture or bias of GC-IRMS measurements. Nevertheless, this demonstrates the importance of testing the accuracy of GCIRMS measurements of atmospheric VOCs. Unfortunately the number of published comparisons between artificial VOC mixtures with known isotope ratios and GC-IRMS measurements is limited, a consequence of the substantial resources and effort required to prepare test mixtures with known iso- tope ratios and the unavailability of certified or otherwise well characterized reference mixtures suitable for such tests. This supports the necessity for creating reference materials for isotope ratio analysis of organic compounds in the atmosphere as pointed out by Gensch et al. (2014).

The measurements conducted over a semi-rural area demonstrate the importance of accurate measurements at low mixing ratios to avoid bias and lack of representativeness of the measurements. Higher mixing ratios often are the result of substantial impact of nearby sources and therefore have carbon isotope ratios close to the isotopic composition of emissions. Inability to measure $\delta^{13} \mathrm{C}$ for VOCs at low mixing ratios will therefore bias the $\delta^{13} \mathrm{C}$ observations towards the source composition and underestimate the role of chemical processing, which results in enrichment of ${ }^{13} \mathrm{C}$.

Overall, the simplicity and affordability of the developed sampling and sample processing system is a valuable step towards the possibility of a wider application of stable carbon isotope measurements in studies of ambient VOCs. However, it should be noted that GC-IRMS instrumentation is still demanding and expensive. Nevertheless, due to the option to collect VOCs from large volumes of air that results in larger sample masses, the need for highly sensitive GC-IRMS instrumentation might not be critical. This is an important step towards establishing VOC isotope ratio measurements as a standard technique in atmospheric chemistry.

Acknowledgements. This work was supported financially by the Canadian Natural Science and Engineering Research Council (NSERC) and the Canadian Foundation for Climate and Atmospheric Sciences (CFCAS). We also thank D. Wang from the National Research Council Canada for providing VOC calibration standards.

Edited by: P. Herckes

\section{References}

Anderson, R., Czuba, E., Ernst, D., Huang, L., Thompson, A., and Rudolph, J.: Method for measuring carbon kinetic isotope effects of gas-phase reactions of light hydrocarbons with the hydroxyl radical, J. Phys. Chem. A, 107, 6191-6199, 2003.

Anderson, R., Huang, L., Iannone, R., Thompson, A., and Rudolph, J.: Carbon kinetic isotope effects in the gas phase reactions of light alkanes and ethene with the $\mathrm{OH}$ radical at $296 \pm 4$ K, J. Phys. Chem. A, 11537-11544, 2004.

Atkinson, R.: Atmospheric chemistry of VOCs and $\mathrm{NO}_{x}$, Atmos. Environ., 34, 2063-2101, 2000.

Bahlmann, E., Weinberg, I., Seifert, R., Tubbesing, C., and Michaelis, W.: A high volume sampling system for isotope determination of volatile halocarbons and hydrocarbons, Atmos. Meas. Tech., 4, 2073-2086, doi:10.5194/amt-4-2073-2011, 2011. 
Bill, M., Conrad, M. E., and Goldstein, A. H.: Stable carbon isotope composition of atmospheric methyl bromide, Geophys. Res. Lett., 31, L04109, doi:10.1029/2003GL018639, 2004.

Craig, H.: Isotopic standards for carbon and oxygen and correction factors for mass-spectrometric analysis of carbon dioxide, Geochim. Cosmochim. Ac., 12, 133-149, 1957.

Czapiewski, C. V., Czuba, E., Huang, L., Ernst, D., Norman, A. L., Koppmann, R., and Rudolph, J.: Isotopic composition of nonmethane hydrocarbons in emissions from biomass burning, J. Atmos. Chem., 43, 45-60, 2002.

de Gouw, J. A., Middlebrook, A. M., Warneke, C., Goldan, P. D., and Kuster, W. C.: Budget of organic carbon in a polluted atmosphere, J. Geophys. Res, 110, D16305, doi:10.1029/2004JD005623, 2005.

Eckstaedt, C., Grice, K., Ioppolo-Armanios, M., Chidlow, G., and Jones, M.: $\delta \mathrm{D}$ and $\delta{ }^{13} \mathrm{C}$ analyses of atmospheric volatile organic compounds by thermal desorption gas chromatography isotope ratio mass spectrometry, J. Chromatogr A, 1218, 6511-6517, 2011.

Eckstaedt, C. V., Grice, K., Ioppolo-Armanios, M., Kelly, D., and Gibberd, M.: Compound specific carbon and hydrogen stable isotope analyses of volatile organic compounds in various emissions of combustion processes, Chemosphere, 89, 1407-1413, 2012.

Fisseha, R., Spahn, H., Wegener, R., Hohaus, T., Brasse, G., Wissel, H., Tillmann, R., Wahner, A., Koppmann, R., and KiendlerScharr, A.: Stable carbon isotope composition of secondary organic aerosol from b-pinene oxidation, J. Geophys. Res., 114, D02304, doi:10.1029/2008JD011326, 2009.

Forstener, H. J., Flagan, R. C., and Seinfeld, J. H.: Secondary organic aerosol from the photooxidation of aromatic hydrocarbons: molecular composition, Environ. Sci. Technol., 31, 1345-1358, 1997.

Gelencsér, A., Siszler, K., and Hlavay, J.: Toluene - benzene concentration ratio as a tool for characterizing the distance from vehicular emission sources, Environ. Sci. Technol., 31, 2869-2872, 1997.

Gensch, I., Kiendler-Scharr, A., and Rudolph, J.: Isotope ratio studies of atmospheric organic compounds: principles, methods, applications and potential, Int. J. Mass Spectrom., 365-366, 206221,2014

Giebel, B. M., Swart, P. K., and Riemer, D. D.: $\delta^{13}$ C Stable isotope analysis of atmospheric oxygenated volatile organic compounds by gas chromatography - isotope ratio mass spectrometry, Anal. Chem., 82, 6797-6806, 2010.

Goldstein, A. and Shaw, S.: Isotopes of volatile organic compounds: an emerging approach for studying atmospheric budgets and chemistry, Chem. Rev., 103, 5025-5048, 2003.

Guenther, A., Geron, C., Pierce, T., Lamb, B., Harley, P., and Fall, R.: Natural emissions of non-methane volatile organic compounds, carbon monoxide, and oxides of nitrogen from North America, Atmos. Environ., 34, 2205-2230, 2000.

Helmig, D., Tanner, D. M., Honrath, R. E., Owen, R. C., and Parrish, D. D.: Nonmethane hydrocarbons at Pico Mountain, Azores: 1. Oxidation chemistry in the North Atlantic region, J. Geophys Res., 113, D20S91, doi:10.1029/2007JD008930, 2008.

Honrath, R. E., Helmig, D., Owen, R. C., Parrish, D. D., and Tanner, D. M.: Nonmethane hydrocarbons at Pico Mountain, Azores: 2. Event-specific analyses of the impacts of mixing and photo- chemistry on hydrocarbon ratios, J. Geophys Res., 113, D20S92, doi:10.1029/2008JD009832, 2008.

Hurley, M. D., Sokolov, O., Wallington, T. J., Takekawa, H., Karasawa, Klotz, B., Barnes, I. A. N., and Becker, K. H.: Organic aerosol formation during the atmospheric degradation of toluene, Environ. Sci. Technol., 35, 1358-1366, 2001.

Iannone, R., Anderson, R. S., Rudolph, J., Huang, L., and Ernst, D.: The carbon kinetic isotope effects of ozone-alkene reactions in the gas-phase and the impact of ozone reactions on the stable carbon isotope ratios of alkenes in the atmosphere, Geophys. Res. Lett., 30, 1684 doi:10.1029/2003GL017221, 2003.

Iannone, R., Anderson, R. S., Vogel, A., Eby, P. S., Whiticar, M. J., and Rudolph, J.: The hydrogen kinetic isotope effects of the reactions of n-alkanes with chlorine atoms in the gas phase, J. Atmos. Chem., 50, 121-138, 2005.

Iannone, R., Koppmann, R., and Rudolph, J.: Technique for atmospheric measurements of stable carbon isotope ratios of isoprene, methacrolein, and methyl vinyl ketone, J. Atmos. Chem., 58, 181-202, 2007.

Iannone, R., Koppmann, R., and Rudolph, J.: ${ }^{12} \mathrm{C} /{ }^{13} \mathrm{C}$ kinetic isotope effects of the gas-phase reactions of isoprene, methacrolein, and methyl vinyl ketone with $\mathrm{OH}$ radicals, Atmos. Environ., 43, 3103-3110, 2009.

Iannone, R., Koppmann, R., and Rudolph, J.: Stable carbon kinetic isotope effects for the production of methacrolein and methyl vinyl ketone from the gas-phase reactions of isoprene with ozone and hydroxyl radicals, Atmos. Environ., 44, 4135-4141, 2010.

Irei, S., Huang, L., Collin, F., Zhang, W., Hastie, D., and Rudolph, J.: Flow reactor studies of the stable carbon isotope composition of secondary particulate organic matter generated by $\mathrm{OH}$-radical-induced reactions of toluene, Atmos. Environ., 40, 5858-5867, 2006.

Jang, M. and Kamens, R. M.: Characterization of secondary aerosol from the photooxidation of toluene in the presence of $\mathrm{NO}_{\mathrm{x}}$ and 1-propene, Environ. Sci. Technol, 35, 3626-3639, 2001.

Jenkin, M. E. and Clemitshawb, K. C.: Ozone and other secondary photochemical pollutants: chemical processes governing their formation in the planetary boundary layer, Atmos. Environ., 34, 2499-2527, 2000.

Jobson, B. T., Parrish, D. D., Goldan, P., Kuster, W., Fehsenfeld, F. C., Blake, D. R., Blake, N. J., and Niki, H.: Spatial and temporal variability of nonmethane hydrocarbon mixing ratios and their relation to photochemical lifetime, J. Geophys. Res., 103, 13,557-13,567, 1998.

Jordan, C., Fitz, E., Hagan, T., Sive, B., Frinak, E., Haase, K., Cottrell, L., Buckley, S., and Talbot, R.: Long-term study of VOCs measured with PTR-MS at a rural site in New Hampshire with urban influences, Atmos. Chem. Phys., 9, 4677-4697, doi:10.5194/acp-9-4677-2009, 2009.

Kawashima, H. and Murakami, M.: Measurement of the stable carbon isotope ratio of atmospheric volatile organic compounds using chromatography, combustion, and isotope ratio mass spectrometry coupled with thermal desorption, Atmos. Environ., 89, 140-147, 2014.

Kleinman, L. I., Daum, P. H., Lee, L.-N., Nunnermacker, L. J., Springston, S. R., Weinstein-Lloyd, J., Hyde, P., Doskey, P., Rudolph, J., Fast, J., and Berkowitz, C.: Photochemical age determinations in the Phoenix metropolitan area, J. Geophys. Res., 108, 4096, doi:10.1029/2002JD002621, 2003. 
Kornilova, A., Saccon, M., O’Brien, J. M., Huang, L., and Rudolph, J.: Stable carbon isotope ratios and the photochemical age of atmospheric volatile organic compounds, AtmosphereOcean, doi:10.1080/07055900.2013.822787, 2013.

Li, Q., Wang, W., Zhang, H.-W., Wang, Y.-J., Wang, B., Li, L., Li, H.-J., Wang, B.-J., Zhan, J., Wu, M., and Bi, X.-H.: Development of a compound-specific carbon isotope analysis method for 2-methyltetrols, biomarkers for secondary organic aerosols from atmospheric isoprene, Anal. Chem., 82, 6764-6769, 2010.

Lurmann, F. W. and Main, H. H.: Analysis of the ambient VOC data collected in the Southern California Air Quality Study, California Air Resources Board, 1992.

Matthews, D. E. and Hayes, J. M.: Isotope-ratio-monitoring gas chromatography-mass spectrometry, Anal. Chem., 50, 14651473, 1978.

McKeen, S. A. and Liu, S. C.: Hydrocarbon ratios and photochemical history of air masses, Geophys. Res. Lett., 20, 2363-2366, 1993.

McKeen, S. A., Liu, S. C., Hsie, E.-Y., Lin, X., Bradshaw, J. D., Smyth, S., Gregory, G. L., and Blake, D. R.: Hydrocarbon ratios during PEM-WEST A: a model perspective, J. Geophys. Res., 101, 2087-2109, 1996.

Moukhtar, S., Saccon, M., Kornilova, A., Irei, S., Huang, L., and Rudolph, J.: Method for determination of stable carbon isotope ratio of methylnitrophenols in atmospheric particulate matter, Atmos. Meas. Tech., 4, 2453-2464, doi:10.5194/amt-4-2453-2011, 2011.

Niedojadlo, A., Kurtenbach, R., and Wiesen, P.: How Reliable are Emission Inventories? Field Observations versus Emission Predictions for NMVOCs, Springer, Netherlands, 2008.

Norman, A. L., Hopper, J. F., Blanchard, P., Ernst, D., Brice, K., Alexandrou, N., and Klouda, G.: The stable carbon isotope composition of atmospheric PAHs, Atmos. Environ., 33, 2807-2814, 1999.

Parrish, D. D., Stohl, A., Forster, C., Atlas, E. L., Blake, D. R., Goldan, P. D., Kuster, W. C., and de Gouw, J. A.: Effects of mixing on evolution of hydrocarbon ratios in the troposphere, J. Geophys. Res., 112, D10S34, doi:10.1029/2006JD007583, 2007.

Piccot, S. D., Watson, J. J., and Jones, J. W.: A global inventory of volatile organic compound emissions from anthropogenic sources, J. Geophys. Res., 97, 9897-9912, 1992.

Redeker, K. R., Davis, S., and Kalin, R. M.: Isotope values of atmospheric halocarbons and hydrocarbons from Irish urban, rural, and marine locations, J. Geophys. Res., 112, D16307, doi:10.1029/2006JD007784, 2007.

Reimann, S. and Lewis, A.: Anthropogenic VOCs, in: Volatile Organic Compounds in the Atmosphere, edited by: Koppmann, R., Blackwell Publishing Ltd, Oxford, 2007.

Roberts, J. M., Fehsenfeld, F. C., Liu, S. C., Bollinger, M. J., Hahn, C., Albritton, D. L., and Sievers, R. E.: Measurements of aromatic hydrocarbon ratios and $\mathrm{NO}_{\mathrm{X}}$ concentrations in the rural troposphere: observation of air mass photochemical aging and $\mathrm{NO}_{\mathrm{x}}$ removal, Atmos. Environ., 18, 2421-2432, 1984.

Rogers, K. M. and Savard, M. M.: Detection of petroleum contamination in river sediments from Quebec City region using GCIRMS, Org. Geochem., 30, 1559-1569, 1999.

Rudolphb, J.: Tropospheric chemistry and composition: aliphatic hydrocarbons, in: Encyclopedia Atmospheric Sciences, edited by: Holton, J. R., Pyle, J., and Curry, J. A., Academic Press, London, UK, 2355-2364, 2002.

Rudolph, J.: Gas chromatography-isotope ratio mass spectrometry, in: Volatile Organic Compounds in the Atmosphere, edited by: Koppmann, R., Blackwell Publishing Ltd, Oxford, 2007.

Rudolph, J. and Czuba, E.: On the use of isotopic composition measurements of volatile organic compounds to determine the "photochemical age" of an air mass, Geophys. Res. Lett., 27, 38653868, 2000.

Rudolph, J. and Johnen, F. J.: Measurements of light atmospheric hydrocarbons over the Atlantic in regions of low biological activity, J. Geophys. Res., 95, 20583-20591, 1990.

Rudolph, J., Lowe, D. C., Martin, R. J., and Clarkson, T. S.: A novel method for the compound specific determination of $\delta^{13} \mathrm{C}$ in volatile organic compounds at ppt levels in ambient air, Geophys. Res. Lett., 24, 659-662, 1997.

Rudolph, J., Czuba, E., Norman, A. L., Huang, L., and Ernst, D.: Stable carbon isotope composition of nonmethane hydrocarbons in emissions from transportation related sources and atmospheric observations in an urban atmosphere, Atmos. Environ., 36, 11731181, 2002.

Rudolph, J., Anderson, R. S., Czapiewski, K. V., Czuba, E., Ernst, D., Gillespie, T., Huang, L., Rigby, C., and Thompson, A. E.: The stable carbon isotope ratio of biogenic emissions of isoprene and the potential use of stable isotope ratio measurements to study photochemical processing of isoprene in the atmosphere, J. Atmos. Chem, 44, 39-55, 2003.

Saito, T., Tsunogai, U., Kawamura, K., Nakatsuka, T., and Yoshida, N.: Stable carbon isotopic compositions of light hydrocarbons over the western North Pacific and implication for their photochemical ages, J. Geophys. Res., 107, 4040, doi:10.1029/2000JD000127, 2002.

Saito, T., Kawamura, K., Tsunogai, U., Chen, T.-Y., Matsueda, H., Nakatsuka, T., Gamo, T., Uematsu, M., and Huebert, B. J.: Photochemical histories of nonmethane hydrocarbons inferred from their stable carbon isotope ratio measurements over east Asia, J. Geophys. Res., 114, D11303, doi:10.1029/2006JD007784, 2009.

Santrock, J., Studley, S. A., and Hayes, J. M.: Isotopic analyses based on the mass spectra of carbon dioxide, Anal. Chem., 57, 1444-1448, 1985.

Sawyer, R. F., Harley, R. A., Cadle, S. H., Norbeck, J. M., Slott, R., and Bravo, H. A.: Mobile sources critical review: 1998 NARSTO assessment, Atmos. Environ., 34, 2161-2181, 2000.

Smallwood, B. J., Philp, R. P., and Allen, J. D.: Stable carbon isotopic composition of gasolines determined by isotope ratio monitoring gas chromatography mass spectrometry, Org. Geochem., 33, 149-159, 2002.

Smith, D. F., McIver, C. D., and Kleindienst, T. E.: Primary product distribution from the reaction of hydroxyl radicals with toluene at ppb $\mathrm{NO}_{x}$ mixing ratios, J. Atmos. Chem., 31, 349-350, 1998.

Stein, O. and Rudolph, J.: Modelling and interpretation of stable carbon isotope ratios of ethane in global chemical transport models, J. Geophys. Res., 112, D14308, doi:10.1029/2006JD008062, 2007.

Thompson, A.: Stable carbon isotope ratios of nonmethane hydrocarbons and halocarbons in the atmosphere, $\mathrm{PhD}$ thesis, York University, 2003.

Thompson, A., Rudolph, J., Rohrer, F., and Stein, O.: Concentration and stable carbon isotopic composition of ethane and 
benzene using a global three-dimensional isotope inclusive chemical tracer model, J. Geophys. Res.-Atmos., 108, 4373, doi:10.1029/2002JD002883, 2003.

Turner, N., Jones, M., Grice, K., Dawson, D., IoppoloArmanios, M., and Fisher, S.: $\delta^{13} \mathrm{C}$ of volatile organic compounds (VOCS) in airborne samples by thermal desorptiongas chromatography-isotope ratio-mass specrometry (TD-GCIR-MS), Atmos. Environ., 40, 3381-3388, 2006.
Wintel, J., Hösen, E., Koppmann, R., Krebsbach, M., Hofzumahaus, A., and Rohrer, F.: Stable carbon isotope ratios of toluene in the boundary layer and the lower free troposphere, Atmos. Chem. Phys., 13, 11059-11071, doi:10.5194/acp-13-11059-2013, 2013.

Zuiderweg, A., Holzinger, R., and Röckmann, T.: Analytical system for stable carbon isotope measurements of low molecular weight $\left(\mathrm{C}_{2}-\mathrm{C}_{6}\right)$ hydrocarbons, Atmos. Meas. Tech., 4, 11611175, doi:10.5194/amt-4-1161-2011, 2011. 